REVISÃO

\title{
NUTRIÇÃO MINERAL E QUALIDADE DO FRUTO DE ALGUMAS FRUTÍFERAS TROPICAIS: \\ GOIABEIRA, MANGUEIRA,BANANEIRA E MAMOEIRO'
}

\author{
JESUS AULAR ${ }^{2} \&$ WILLIAM NATALE ${ }^{3}$
}

RESUMO- A qualidade dos frutos é o resultado da somatória da ação de vários fatores, em especial do efeito individual e combinado dos nutrientes. $\mathrm{O}$ adequado atendimento das exigências nutricionais faz com que as plantas frutíferas possam expressar todo seu potencial genético. Sendo assim, nas fruteiras tropicais, têm sido feitas pesquisas para avaliar os efeitos dos nutrientes minerais sobre a qualidade dos frutos; porém as mesmas aparecem dispersas. O objetivo desta revisão foi compilar e apresentar informações sobre os efeitos dos nutrientes minerais na qualidade dos frutos da goiabeira, da mangueira, da bananeira e do mamoeiro. Assim, são apresentadas informações sobre a influência dos elementos essenciais na cor, aroma, forma, tamanho, aparência, resistência à penetração, incidência de doenças, desordens fisiológicos, características físico-químicas e vida útil da pós-colheita dos frutos.

Termos para: Macronutrientes, Micronutrientes, características físicas, características químicas.

\section{MINERAL NUTRITION AND FRUIT QUALITY OF SOME TROPICAL FRUIT: GUAVA, MANGO, BANANA, AND PAPAYA}

\begin{abstract}
Fruit quality is the result of the action of several factors, in particular the individual and combined effect of mineral nutrients. The proper evaluation of mineral nutritional requirements causes that fruit plants can express all their genetic potential. Thus, a research has been conducted in tropical fruit, for evaluating the influence of mineral nutrients on fruit quality; however, they appear dispersed. The objective of this review was to compile and report the effects of mineral nutrients on fruit quality of guava, mango, banana and papaya. Consequently, information about the influence of the essential elements in color, flavor, shape, size, appearance, penetration resistance, physiological disturbs disease incidence, physicochemical characteristics and lifetime of post - harvest fruit are presented.
\end{abstract}

Index terms: Macro-element; Micro-element, physical-chemical characteristics. 


\section{INTRODUÇÃO}

A aplicação de adubos faz-se necessária quando a exigência em nutrientes pelo pomar é maior que a capacidade que o solo tem para atender a essa demanda, o que é quase uma regra, especialmente nas regiões tropicais, como no Brasil, cujos solos são caracterizados pela baixa fertilidade (NATALE et al. 2012). Porém, determinar as necessidades em nutrientes de uma cultura é um desafio constante. Apesar de os elementos minerais exigidos para a adequada nutrição serem os mesmos para todos os vegetais, as quantidades necessárias são muito variáveis de uma cultura para outra, sendo função de características da espécie, das condições edafoclimáticas, da capacidade produtiva, do ciclo da frutífera, dentre outras. De acordo com a FAO (2009), cerca de $50 \%$ da responsabilidade pelo aumento do rendimento agrícola deve-se aos fertilizantes. A qualidade das frutas é uma característica subjetiva e depende fundamentalmente do consumidor a que se destina. Entretanto, grosso modo, a qualidade deve atender aos seguintes objetivos: alimentar, promover satisfação e provocar sensações sensoriais únicas. $\mathrm{O}$ fator qualidade não é facilmente definido ou medido, como a produção, visto ter significados diversos, com ênfases variadas, para diferentes pessoas. A qualidade não é obtida por acaso, sendo resultado da somatória de vários fatores, em especial do balanço de nutrientes. Segundo Malavolta (2006), a qualidade é o conjunto de características relacionadas ao valor nutritivo, comercial ou industrial do produto agrícola ou, no caso das frutas, que acentua suas propriedades organolépticas.

A determinação da qualidade consiste na avaliação de diferentes características externas e internas dos frutos, destacando-se o tamanho, o formato, a aparência, a cor, a textura, a uniformidade, a firmeza (externos), além do aroma, do sabor, do valor nutricional, da acidez, do teor de sólidos solúveis totais (internos). Entretanto, a aparência das frutas é de grande importância, uma vez que o consumidor "come com os olhos", e somente compra o que lhe parece mais atrativo. Por outro lado, segundo o IBRAF (2013), o que tem sido constatado é que o apelo à saúde e ao bem-estar, ou seja, de que as frutas são alimentos saúdáveis, não é suficiente. É preciso oferecer mais, fundamentalmente sabor, que é o fator-chave para que se tenha prazer de comer.

As características de qualidade têm uma amplitude geneticamente definida, não podendo o homem interferir além do que determina a capacidade dos genes da frutífera. Porém, a expressão das mesmas depende de vários fatores, com destaque para o adequado atendimento das exigências nutricionais, a fim de que as plantas possam expressar todo seu potencial genético.

A literatura apresenta informações sobre a participação dos elementos essenciais no sabor, cor, aroma, forma, tamanho, aparência, resistência a pragas e doenças, armazenamento pós-colheita das frutas, etc. Isso é justificado pelo papel específico que cada nutriente desempenha no metabolismo vegetal. São exemplos disso, a participação do cálcio na firmeza dos frutos ou do nitrogênio em seu tamanho. Por outro lado, não existe um comportamento único para os efeitos dos nutrientes sobre a qualidade. As condições edafoclimáticas, a cultivar e a dose do nutriente são determinantes da qualidade. A máxima produção e a melhor qualidade dos frutos dependem, também, do equilíbrio entre os nutrientes. Desse modo, a relação (proporção) entre os elementos no tecido vegetal desempenha papel mais importante que o teor absoluto de cada nutriente.

$\mathrm{Na}$ Tabela 1, estão apresentados, de forma resumida, os compostos e/ou funções dos elementos essenciais nos processos metabólicos que afetam o desenvolvimento das características de qualidade dos frutos.

A literatura apresenta grande variação de resultados sobre os efeitos da aplicação de fertilizantes na qualidade dos produtos agrícolas e, em especial, dos frutos. É importante destacar que muitos aspectos ligados à qualidade são influenciados de maneira limitada pela adubação, ao passo que as condições climáticas exercem efeito mais marcante, o que pode explicar a divergência dos resultados de pesquisa.

Frequentemente, porém, os estudos agronômicos e hortícolas relegam a um segundo plano os efeitos dos fertilizantes sobre a qualidade, apesar de bem conhecida a participação de alguns nutrientes em processos metabólicos que afetam essa característica fundamental dos frutos.

Por outro lado, o aumento da produção à custa da elevação das doses de adubo pode provocar redução na qualidade dos frutos, afetando o tamanho, a resistência ao transporte e o armazenamento, a coloração interna e externa, e o teor de sólidos solúveis totais. Esse último aspecto é de grande importância nos frutos, tanto para consumo in natura como para o processamento industrial, visto que elevados teores desses constituintes na matéria-prima implicam menor adição de açúcares, menor tempo de evaporação da água, menor gasto de energia e maior rendimento agroindustrial, resultando em maior economia no processamento.

O objetivo desta revisão foi compilar 
e apresentar informações sobre os efeitos dos nutrientes minerais na qualidade dos frutos de algumas frutíferas tropicais: goiabeira, mangueira, bananeira e mamoeiro.

\section{RESULTADOS DE PESQUISA COM A CULTURA DA GOIABA}

As pesquisas relacionadas ao aspecto nutricional e, em particular, sobre os efeitos da adubação na qualidade dos frutos da goiabeira são escassas. Natale et al. (1995a) conduziram experimentos em dois pomares de goiabeiras no Estado de São Paulo, Brasil, sendo o primeiro com a cultivar Rica, no município de Jaboticabal (área de Argissolo Vermelho-Amarelo), e o segundo, com a cultivar Paluma, em São Carlos (área de Latossolo Vermelho-Amarelo). Ambos os pomares tinham um ano de idade, e os ensaios foram conduzidos por três anos consecutivos, empregando-se, isoladamente, doses crescentes de nitrogênio $(\mathrm{N})$, fósforo $(\mathrm{P})$ e potássio $(\mathrm{K})$. Os tratamentos não mostraram diferenças significativas no teor de sólidos solúveis (SST) totais em ambas as cultivares. Os frutos da goiabeira cv. Rica apresentaram SST entre 8,0 e 10,8 ${ }^{\circ}$ Brix , enquanto a cv. Paluma apresentou valores entre 8,4 e 9,65 ${ }^{\circ}$ Brix. Esses resultados divergem de alguns encontrados na literatura. Wagh e Mahajan (1987) observaram redução no teor de SST em frutos de goiabeiras na Índia, enquanto Villasurda e Baluyut (1990) obtiveram aumentos em variedades das Filipinas, em razão da adubação nitrogenada.

Apesar da conhecida influência do $\mathrm{K}$ em aspectos relacionados à qualidade das frutas, os teores de SST, determinados nos experimentos de Natale et al. (1995a), não apresentaram efeitos significativos nos tratamentos. Resultados contrastantes foram relatados por Wagh e Mahajan (1987), que observaram incremento nos SSTs dos frutos quando houve aplicação de fertilizante potássico em pomares de goiabeiras da Índia. Por outro lado, Walling e Sanyal (1995) não observaram efeito da adubação com $\mathrm{N}$ e K, isoladamente, mas sua interação proporcionou aumentos substanciais nos SSTs das goiabas.

O tamanho dos frutos é outra característica qualitativa importante, especialmente para o consumo in natura. Com o objetivo de avaliar a influência da adubação nitrogenada sobre esse aspecto, Natale et al. (1995b) conduziram ensaio durante três anos consecutivos, empregando doses crescentes de N. Os autores observaram respostas positivas apenas na última safra, com elevação do número de frutos e aumento da massa média dos mesmos, em função do incremento das doses de fertilizante nitrogenado.
Tais resultados estão de acordo com os relatados por Wagh e Mahajan (1987).

O efeito da adubação potássica sobre o tamanho dos frutos da goiabeira foi tema de outro experimento desenvolvido por Natale et al. (1996). O estudo foi conduzido por três anos, e os autores obtiveram aumento da massa média das goiabas em função do incremento das doses de K, apenas no último cíclo. Resultados semelhantes são relatados na literatura por Shikhamany et al. (1986). Entretanto, a exata função do $\mathrm{K}$ nesse incremento é desconhecida. Admite-se que o $\mathrm{K}$ participe das atividades metabólicas relativas à síntese e ao transporte de carboidratos e água para os frutos, resultando em maior massa.

Em experimento conduzido por três anos consecutivos com a cultura da goiaba, empregando doses crescentes de adubo fosfatado, Natale et al. (2001) não observaram efeito do nutriente sobre a massa média dos frutos.

Nos solos das regiões tropicais, a reação ácida e a pobreza em cátions básicos, como o cálcio $\mathrm{Ca}$, são uma constante. Nessas condições, a aplicação de calcário é o meio mais barato, rápido e eficiente para sanar ambos os problemas (RAIJ, 1991). O cálcio é um macronutriente vegetal que desempenha função bioquímica importante, favorecendo numerosos processos metabólicos, como: formação da parede celular, regulação da funcionalidade da membrana celular, constituição da lamela média, além de ativar vários sistemas enzimáticos, contribuindo, assim, para o adequado desenvolvimento das plantas (MENGEL; KIRKBY, 2000).

Em frutíferas, o Ca desempenha papel fundamental, pois afeta a qualidade do produto final e sua capacidade de armazenamento depois da colheita. Há relação direta entre o conteúdo de $\mathrm{Ca}$ nos frutos e o amolecimento, firmeza e tempo de vida útil de prateleira. Quando o conteúdo de Ca no fruto é baixo, o metabolismo respiratório aumenta e acelera a maturação e a senescência. Outro aspecto da importância desse macronutriente, na estabilidade da membrana, é que seu baixo conteúdo em órgãos de reserva induz à alta permeabilidade da membrana e permite a difusão de solutos desses tecidos (MARSCHNER, 1995).

A baixa eficiência das goiabas para a absorção do Ca, aplicado nos frutos depois da colheita, foi demonstrada por Lima (2003) em ensaio com emprego de ${ }^{45} \mathrm{Ca}$. As plantas absorvem $\mathrm{Ca}$ do solo e transportam-no até a parte aérea através da corrente transpiratória (via xilema). O nutriente é preferencialmente transportado para os pontos de crescimento vegetativo (brotos) e folhas, em relação 
aos frutos. Em condições de baixa disponibilidade desse nutriente no solo (solos ácidos), excesso de umidade (baixa transpiração) ou estresse hídrico (competição pela seiva), os teores de Ca nos frutos podem não atingir valores adequados (MENGEL; KIRKBY, 2000).

Considerando-se que a redistribuição de $\mathrm{Ca}$ das folhas para os frutos é, em geral, fisiologicamente insignificante (MARSCHNER, 1995) e, ainda, que características anatômicas e morfológicas das folhas da goiabeira e de seus frutos (MÔRO et al., 2003) podem interferir em seu metabolismo, é oportuno compreender o papel do $\mathrm{Ca}$ em nível ultracelular. Com esse objetivo, frutos foram coletados de um experimento de calagem, conduzido em Latossolo Vermelho distrófico típico. Avaliaram-se frutos de goiabeiras cv. Paluma, cultivadas em área sem aplicação de calcário $(\mathrm{V}=23 \%$; Ca no solo $=8$ $\mathrm{mmol} \mathrm{dm}^{-3}$ ) e, em área adjacente, que recebeu corretivo de acidez na implantação do pomar (V $=66 \%$; Ca no solo $=30 \mathrm{mmol} \mathrm{dm}^{-3}$ ). Nas goiabas colhidas de plantas que receberam a aplicação de calcário, observou-se que as paredes celulares e as lamelas médias estavam bem definidas e estruturadas, com as células unidas. Nos frutos colhidos das goiabeiras que não receberam o corretivo de acidez, as paredes celulares apresentavam perda de estrutura e desorganização da lamela média, evidenciando a importância do Ca na estrutura dos frutos. Os resultados das observações microscópicas deste estudo explicam, em nível celular, os efeitos positivos do Ca relatados posteriormente por Prado et al. (2005), que constataram que a presença de $\mathrm{Ca}$ reduziu as perdas de massa de matéria fresca, bem como aumentou a firmeza, melhorando a qualidade dos frutos da goiabeira na pós-colheita.

\section{RESULTADOS DE PESQUISA COM A CULTURA DA MANGA}

Léchaudel e Joas (2007) indicam que entre os principais fatores de pré-colheita que determinam a qualidade do fruto da mangueira destacam-se: a luz, a temperatura, a disponibilidade de água e de carbono, o raleio dos frutos na planta e o manejo da irrigação. Esses fatores podem afetar, também, o modo de ação dos nutrientes minerais, refletindo na qualidade.

$\mathrm{O} \mathrm{N}$ determina, em grande parte, a cor das mangas. Para estudar o problema da permanência da cor verde no fruto maduro e investigar se o uso de $\mathrm{N}$ está relacionado com essa questão, e, ainda, com a incidência de antracnose na manga 'Kensington', foi realizado um experimento na Austrália (NGUYEN et al., 2004). Os resultados indicaram que o incremento da aplicação de $\mathrm{N}$ aumentou o problema das frutas maduras com coloração verde, bem como elevou a incidência da doença. Não se observaram efeitos significativos da adubação sobre os SSTs e ATTs da polpa, sugerindo que a aplicação de $\mathrm{N}$ ao solo poderia ser reduzida para melhorar a cor da casca dos frutos. O distúrbio fisiológico, mais conhecido como colapso interno, tem aparecido com frequência nos pomares brasileiros, especialmente naqueles com mangueiras americanas, melhoradas geneticamente, enquanto nas mangas fibrosas, mais rústicas, como 'Espada' e 'Coquinho', o problema é praticamente ausente (EVANGELISTA, 1992).

Além do patrimônio genético, associado ao ambiente, algumas pesquisas têm indicado que o balanço de nutrientes desempenha papel fundamental para diminuir a incidência do colapso interno. $\mathrm{O} \mathrm{Ca}$ é o elemento mais estudado, devido ao seu papel na manutençao da integridade das membranas, e Van Eeden (1992) encontrou relação direta entre a deficiência de $\mathrm{Ca}$ e o maior aparecimento desse disturbio em frutos de mangueira, caracterizado por desorganização das células e pela ruptura da parede celular.

Considerando a importante participação do $\mathrm{Ca}$ em aspectos ligados à qualidade dos frutos, algumas pesquisas são relatadas na literatura, aplicando-se $\mathrm{Ca}$ em pré ou pós-colheita nas mangas. Evangelista et al. (2000), avaliando a aplicação de $\mathrm{Ca}(0,2,5$ e $5,0 \%)$ em pré-colheita, observaram alteração na atividade das enzimas poligalacturose, pectinametilesterase e $b$-galactosidase em 'Tommy Atkins', bem como no armazenamento das mangas. Os frutos que receberam o tratamento com $\mathrm{CaCl}_{2}$ a $5,0 \%$ apresentaram maior firmeza. Os autores não observaram diferenças importantes na atividade da poligalacturose, porém, quanto maior o teor de cálcio nos frutos, menor a atividade da $b$-galactosidase.

Júnior e Chitarra (1999) estudaram o efeito da aplicação de cloreto de cálcio (0,2 e 4\%) em frutos de mangueiras 'Tommy Atkins', constatando aumento dos teores de $\mathrm{Ca}$ na casca das mangas, com o incremento das doses de $\mathrm{Ca}$, com consequente melhoria da aparência externa dos frutos; entretanto, a qualidade final não melhorou. Uma das possíveis explicações para a falta de efeitos concretos da pulverização de Ca na amenização dos sintomas do colapso interno em mangas é a ausência de estômatos funcionais nos frutos (DIETZ et al. 1988).

Avaliando a qualidade de mangas 'Tommy Atkins' submetidas à aplicação pré-colheita de $\mathrm{CaCl}_{2}$, Silva e Menezes (2001) não constaram incremento no teor de $\mathrm{Ca}$, bem como efeito do elemento na firmeza da fruta ou na incidência de colapso interno. 
Resultados semelhantes são descritos por Sampaio et al. (1999), que fizeram várias pulverizações de cloreto de cálcio na fase de frutificação das mangueiras, não observando alterações no conteúdo de Ca ou na diminuição do colapso interno dos frutos.

Por outro lado, Evangelista et al. (2002), avaliando pulverizações em pré-colheita com cloreto de cálcio $(0,0 \%, 2,5 \%$ e $5,0 \%)$, em mangueiras 'Tommy Atkins', observaram, através de microscopia eletrônica de transmissão, desestruturação da parede celular e dissolução da lamela média nos frutos que não receberam as pulverizações, enquanto nos tratados com $\mathrm{Ca}$ a estrutura permaneceu escura, indicando a presença de material intercelular. Assim, os frutos que receberam $\mathrm{CaCl}_{2}$ a 5,0\% apresentaram lamela média bem definida e ausência de espaços vazios, mesmo após o armazenamento, mostrando que o elemento contribui para a preservação dessa estrutura.

Diversos fatores podem ser responsabilizados pela ineficiência de aproveitamento do Ca pelas mangueiras, incluíndo-se desde a forma de aplicação até as variações nos teores foliares considerados adequados na literatura. Além disso, condições edafoclimáticas distintas, associadas à variação genética, também devem contribuir para a divergência nos resultados de pesquisas. Dentre os fatores abióticos, a água desempenha papel fundamental na eficiência de aproveitamento do $\mathrm{Ca}$, visto que a maior parte do elemento entra na planta via fluxo de massa. Como o vaso condutor ascendente é o xilema, e a redistribuição do Ca na planta é insignificante, quando há vários drenos envolvidos, e as folhas têm proporcionalmente maior superfície de exposição, o cálcio dirige-se, preferenciamente, a esses órgãos, em detrimento dos frutos. Desse modo, uma das maneiras de amenizar a carência de cálcio é manter a umidade do solo em níveis adequados (suplementando via irrigação, se necessário), bem como aplicar o elemento via solo, cujo meio mais barato e eficaz é através da calagem.

Além dos efeitos individuais do $\mathrm{Ca}$, são encontradas na literatura algumas indicações de que o equilíbrio entre os elementos no interior da planta desempenha papel mais importante que os teores isolados. Nesse sentido, Moraes et al. (2002) avaliaram a relação de equilíbrio entre alguns nutrientes e seus efeitos na ocorrência de distúrbios fisiológicos em mangueira 'Tommy Atkins'. Os autores relataram que os teores de $\mathrm{Ca}$ e $\mathrm{Mg}$ nos frutos sem sintomas foram maiores que naqueles com colapso interno. Apesar de não haver diferenças significativas nos teores isolados de $\mathrm{N}$ e $\mathrm{K}$, as relações $\mathrm{N} / \mathrm{Ca}$ e $\mathrm{K} / \mathrm{Ca}$ foram maiores nos frutos com sintomas de disturbio na polpa e na casca para N/Ca, e na casca das mangas para $\mathrm{K} / \mathrm{Ca}$. A competição entre cátions no solo pode explicar o favorecimento da absorção de potássio, quando este está em concentrações elevadas, em relação ao $\mathrm{Ca}$. Por outro lado, as funções específicas do N no metabolismo vegetal justificam a predisposição das mangueiras para sofrerem de colapso interno, quando a adubação nitrogenada é excessiva ou as relaçõs N/ Ca são altas.

Assis et al. (2004) avaliaram o efeito do equilíbrio nutricional sobre a incidência de distúrbios fisiológicos em manga 'Tommy Atkins', cultivada no Vale do São Francisco. Os autores concluíram que elevados teores de $\mathrm{Ca}$ e $\mathrm{Mg}$, bem como baixas relações $\mathrm{N} / \mathrm{Ca}$ e $\mathrm{K} / \mathrm{Ca}$, tanto na polpa quanto na casca, foram eficientes na prevenção de distúrbios fisiológicos nos frutos; os teores de nutrientes obtidos na casca refletem melhor a condição da fisiopatia do que aqueles observados na polpa dos frutos; os valores de SST e a relação SST/ATT, determinados nos frutos com sintomas, foram muito mais elevados do que naqueles sem sintomas, devido à sobrematuração.

Apesar de não haver concenso sobre as provaveis causas do distúrbio fisiológico e a literatura especializada no assunto ser ainda escassa, pode-se inferir, através das informações acima relatadas, que cuidados com a adubação e a calagem da mangueira são extremamente importantes, podendo, em princípio, reduzir a incidência do colapso interno.

Para determinar o efeito da aplicação foliar de micronutrientes ferro (Fe), Boro (B) e Zinco ( $\mathrm{Zn}$ ) sobre a qualidade dos frutos da mangueira, avaliou-se a produção de 21 árvores da cv. 'Dusehri', as quais foram submetidas à aplicação foliar de diferentes combinações de $\mathrm{FeSO}_{4}, \mathrm{ZnSO}_{4}$ e $\mathrm{H}_{3} \mathrm{BO}_{3}$, em préfloração e na fase de plena floração, no Paquistão (MOAZZAM et al., 2011). Os resultados revelaram que a aplicação de todos os micronutrientes aumentou significativamente a qualidade dos frutos, comparativamente ao controle. Os autores concluíram que a aplicação foliar combinada de $\mathrm{FeSO}_{4}, \mathrm{H}_{3} \mathrm{BO}_{3}$ e $\mathrm{ZnSO}_{4}$ resultou em mangas menos ácidas, com maior valor de SST e de ácido ascórbico. $\mathrm{O}$ aumento na concentração de $\mathrm{ZnSO}_{4}$ promoveu elevação dos SSTs do fruto, e o aumento na concentração de $\mathrm{FeSO}_{4}$ e $\mathrm{ZnSO}_{4}$ incrementou a percentagem de açúcares totais.

Segundo Bhatt et al. (2012), o Zn e o B destacam-se nas funções que desempenham na formação e na manutenção da qualidade dos frutos da mangueira. Com o objetivo de encontrar uma resposta rápida, via pulverização foliar, para a 
correção de deficiências destes micronutrientes, seja de forma isolada, seja ou combinada, foi conduzido um estudo em Pantnagar, Índia, com a cv. Dashehari. $\mathrm{O}$ experimento envolveu a pulverização foliar de nutrientes na pré-colheita dos frutos. Os tratamentos incluíram $\mathrm{CaCl}_{2}(1,2 \%)$, Borax $(0,5 \%), \mathrm{K}_{2} \mathrm{SO}_{4}$ $(0,5 \%), \mathrm{Ca}\left(\mathrm{NO}_{3}\right)_{2}(1,0 \%), \mathrm{ZnSO}_{4}(0,5 \%), \mathrm{ZnCl}_{2}$ $(0,3 \%)$ e o controle. Os resultados indicaram que as árvores pulverizadas com $0,5 \%$ de bórax mostraram máximo rendimento, peso e volume do fruto, bem como valores superiores de SST, açúcares redutores e não redutores.

\section{RESULTADOS DE PESQUISA COM A CULTURA DA BANANA}

O uso inadequado do $\mathrm{N}$, seja por desbalanceamento, seja em excesso, gera no fruto da bananeira uma qualidade pobre em termos de SST, cor, conteúdo mineral e curta vida útil pós-colheita. Isso pode também tornar a banana mais suscetível aos efeitos das doenças e pragas (GANESHAMURTHY et al., 2011)

Para verificar os efeitos do $\mathrm{N}$ sobre a qualidade do fruto da bananeira, têm sido desenvolvidas várias pesquisas. Assim, Teixeira et al. (2002) avaliaram, nas condições do Estado de São Paulo, Brasil, a resposta da bananeira 'Nanicão' (Musa AAA subgrupo Cavendish) à adubação nitrogenada, submetida à irrigação ou não, durante dois ciclos produtivos consecutivos. Observaram que a irrigação incrementou significativamente a produção de frutas e determinou a resposta do $\mathrm{N}$ quanto à qualidade da fruta. $\mathrm{O} \mathrm{N}$ afetou negativamente o diâmetro dos frutos no primeiro ciclo; porém, isso não ocorreu no segundo ciclo, em que o incremento do $\mathrm{N}$ aumentou o diâmetro do fruto, ajustando-se os valores a uma equação quadrática.

Pinto et al. (2005) avaliaram o efeito de diferentes doses de $\mathrm{N}$ sobre algumas características da produção e físico-químicas do fruto da banana 'Pacovan', não encontrando efeito do $\mathrm{N}$ sobre o peso do cacho, da penca e do número de dedos por cacho; não obstante, com a maior dose de nitrogênio, atingiu-se a máxima relação SST/ Acidez total titulável (ATT).

González et al. (2006), na localidade de 'Palestina', Estado de 'Caldas', Colômbia, estudaram a resposta da Banana da Terra 'África 1' (Musa AAB Mbouroukou) à adubação, via solo, com N, durante um ciclo de produção. Não houve diferença estatística para as variáveis: peso do cacho, número total de dedos por cacho e peso do fruto. Tampouco houve efeito do $\mathrm{N}$ sobre as variáveis de qualidade analisadas.

O P é um dos determinantes da qualidade da banana. Nesse sentido, Crisostomo et al. (2008) avaliaram o efeito da adubação com P sobre a produção e as características dos frutos da bananeira "Pacovan". As doses de $\mathrm{P}$ avaliadas foram: $0 ; 100 ; 200$ e $300 \mathrm{~g} /$ planta/ano de $\mathrm{P}_{2} \mathrm{O}_{5}$. Os autores não encontraram efeito do $\mathrm{P}$ sobre a produção e a qualidade do fruto. No Egito, foi estudado o uso de bactérias que solubilizam P (BSP) (Pseudomonas spp. e Bacillus spp.) e doses de $\mathrm{P}$ $\left(25 \%, 50 \%\right.$ e $\left.75 \% \mathrm{P}_{2} \mathrm{O}_{5}\right)$ em relação à dose comercial $\left(100 \% \mathrm{P}_{2} \mathrm{O}_{5}\right)$, na qualidade dos frutos da banana 'Maghrabi'. Observou-se que, quando utilizadas as bactérias junto com a dose de $25 \% \mathrm{P}_{2} \mathrm{O}_{5}$, houve incremento do número de mãos e dedos por cacho, assim como maior peso, diâmetro do fruto, SST e ATT. Concluiu-se que a inoculação com a BSP reduziu os requerimentos de adubação fosfatada (ATTIA et al., 2009) .

As exigências de $\mathrm{K}$ pelas frutíferas são altas, quando o objetivo é obter elevada produção e, também, que a maior parte das bananas seja comercializável com boa qualidade e adequado comportamento na pós-colheita. A aplicação de K influenciou o tamanho do fruto, a aparência, a cor, o aroma e o sabor, tendo como consequência melhor aceitação pelo consumidor (GANESHAMURTHY et al., 2011)

Entre os efeitos positivos do K, podemse destacar a uniformidade no amadurecimento e a maior resistência aos danos físicos durante $\mathrm{o}$ transporte e o armazenamento. $\mathrm{O} \mathrm{K}$ é considerado o nutriente mais importante na bananeira, devido à grande acumulação nos tecidos desta planta. Assim, o K é o principal cátion nas células da bananeira, mesmo que não desempenhe um papel direto na estrutura das mesmas, age em reações de catálises que são fundamentais, tais como: respiração, formação de clorofila, fotossíntese e regulação hídrica. $\mathrm{O} \mathrm{K}$ tem relação direta com a síntese, o transporte e a acumulação de açúcares, permitindo o crescimento do fruto e determinando sua qualidade (GANESHAMURTHY et al., 2011).

Vários trabalhos sobre o papel do $\mathrm{K}$ na qualidade do fruto da bananeira têm sido feitos. Deste modo, Weerasinghe e Premalal (2002) estudaram a resposta da bananeira cv. Mysore (AAB) à adição de $\mathrm{K}$, confirmando que este elemento afeta o peso, o tamanho e o diâmetro do fruto, assim como o rendimento da planta. Pinto et al. (2005) avaliaram o efeito do K sobre algumas características de produção e físico-químicas do fruto da bananeira 'Pacovan', encontrando que o potássio afetou o número de frutos 
por cacho e a relação SST/ATT.

Estudando a resposta da banana da Terra 'África 1' (Musa AAB Mbouroukou) à adubação potassica, via solo, durante um ciclo de produção, González et al., (2006) não observaram diferenças estatísticas para as variáveis: peso do cacho, número total de dedos por cacho e peso médio de dedos. Tampouco houve efeito individual ou combinado do $\mathrm{N}$ e K sobre as variáveis físico-químicas analisadas. Martins et al. (2011) analisaram o efeito da adubação potássica e da irrigação na produtividade e na qualidade de frutos de bananeiras, cv. Willians, na região do Médio Paranapanema, São Paulo, usando quatro regimes hídricos: sequeiro; $0,7 \mathrm{da}$ evapotranspiração de referência (ETo); 1,4 ETo e 2,1 ETo, combinados com quatro doses de K: 0; 300; 600 e $900 \mathrm{~kg} \mathrm{ha}^{-1} \mathrm{ano}^{-1}$ de $\mathrm{K}_{2} \mathrm{O}$, aplicados semanalmente via fertirrigação. Sob sequeiro, a adubação potássica foi aplicada durante o período chuvoso, parcelada em quatro vezes. Estes autores observaram que a adubação potássica, realizada via fertirrigação, interfere positivamente tanto na produção como na qualidade dos frutos de bananeiras cv. Willians. Além disso, a fertirrigação melhora a eficiência da adubação potássica, quando comparada à adubação sob sequeiro.

São evidentes os efeitos individuais dos elementos minerais sobre a qualidade dos frutos; porém, os efeitos combinados e as interações podem ser mais marcantes. Assim sendo, foi avaliado o efeito do $\mathrm{N}$ e do $\mathrm{P}$ na qualidade dos frutos de bananeiras 'Pacovan', sob irrigação, no primeiro ciclo de cultivo, na chapada do Apodi, no Estado do Ceará, Brasil. A adubação de base consistiu na aplicação de $20 \mathrm{~L} \mathrm{planta}^{-1}$ de esterco de curral, 200 g planta ${ }^{-1}$ de fosfato monoamônico e $100 \mathrm{~g} \mathrm{planta}^{-1}$ de FTE-BR12. A partir de 4,5 meses do plantio, mensalmente, aplicou-se 1/12 das doses de $\mathrm{N}: \mathrm{K}_{2} \mathrm{O}$ $(180: 330 ; 180: 770 ; 420: 330 ; 420: 770 ; 30: 330$; $570: 770 ; 180: 55 ; 420: 1.045$ e $300: 550 \mathrm{~kg} \mathrm{ha}^{-1}$. Observou-se que os teores de SST, açúcares solúveis e ATT das bananas foram afetados pela adubação nitrogenada e potássica (WEBER et al., 2006)

Trabalhos têm sido desenvolvidos considerando a adubação com N, P e K, e sua influência nas características de qualidade da banana. Foram examinados os efeitos desses nutrientes sobre os componentes da produção e da qualidade de bananas 'Prata-Anã', em Matias Cardoso, Minas Gerais, Brasil, onde foram combinadas doses (g/touceira) de N, P e K sendo 1 (controle): 250-45-700, 2: 250-25-700, 3: 250-70-700, 4: 250-100- 700, 5: 250-45-300, 6: 250-45-500, 7: 250-45-1000, 8: 150-45-700, 9: 400-45-700, 10:
600-45-700. Observou-se que as doses de $\mathrm{N}$ ou $\mathrm{P}$ utilizadas pelos fruticultores podem ser reduzidas para 150 ou $25 \mathrm{~g} /$ touceira, respectivamente, sem prejuízo para a produção e a qualidade dos frutos. Por outro lado, as doses de potássio até $1.000 \mathrm{~g} /$ touceira, parceladas semanalmente, proporcionaram aumentos significativos na massa, comprimento total e comercial do fruto (MAIA et al., 2003)

Crisostomo et al. (2008), num solo arenoso do Estado do Ceará, Brasil, avaliaram o efeito da adubação com N, P e K sobre a produção e a qualidade dos frutos da bananeira 'Pacovan'. Os tratamentos consistiram em combinações de $\mathrm{N}(0$; 200; 400 e $600 \mathrm{~g}$ de N), P $(0 ; 100 ; 200$ e $300 \mathrm{~g}$ de $\left.\mathrm{P}_{2} \mathrm{O}_{5}\right)$ e $\mathrm{K}\left(0 ; 350 ; 700\right.$ e $1050 \mathrm{~g}$ de $\left.\mathrm{K}_{2} \mathrm{O}\right)$. No primeiro ciclo de cultivo, a produção, os componentes e os atributos de qualidade dos frutos não foram influenciados pela adubação. Mas, no segundo ciclo, a maioria dos atributos de qualidade foi influenciada positivamente pela adubação.

Al-Harthi e Al-Yahyai (2009), nas condições de Al-Batinah, na zona norte de Oman, avaliaram diferentes doses de adubo NPK para bananeira 'Williams'. Foram testadas três doses para cada macronutriente: $\mathrm{N}(300 ; 600$ e $900 \mathrm{~g}$ de $\mathrm{N} /$ planta/ ano), $\mathrm{P}\left(50 ; 100\right.$ e $150 \mathrm{~g}$ de $\mathrm{P}_{2} 0_{5} /$ planta/ano) e $\mathrm{K}$ (250; 500 e $750 \mathrm{~g}$ de $\mathrm{K}_{2} 0 /$ planta/ano) e considerouse o controle sem adubação. $\mathrm{O}$ tratamento composto por N (600 g/planta/ano), P (100 g/planta/ano) e K $(500 \mathrm{~g} /$ planta/ano) influenciou positivamente sobre o rendimento e a qualidade da fruta, assim como correspondeu aos maiores pesos de cacho, das mãos e do número de dedos por mãos.

$\mathrm{O}$ cálcio determina a integridade da parede celular e, consequentemente, afeta a qualidade do fruto. A "mancha de madurez" dos frutos de bananeira é uma desordem fisiológica causada pela absorção baixa de cálcio por parte da planta nas épocas de seca ou déficit hídrico (DÍAZ et al., 2007).

A aplicação de K via solo na bananeira pressupõe existir adequada quantidade de magnésio $(\mathrm{Mg})$, a fim de evitar o distúrbio fisiológico que faz aparecer sintomas de deficiência deste elemento. Assim, foi avaliado o efeito da aplicação de $\mathrm{K}$ e Mg no rendimento e na qualidade do fruto da bananeira "Prata- Anã'. Consideraram-se dois ciclos e três doses de potássio $\left(0 ; 800\right.$ e $\left.1200 \mathrm{~kg} \mathrm{ha}^{-1} \mathrm{ano}^{-1}\right) \mathrm{e}$ cinco doses de magnésio $(0 ; 60 ; 120 ; 240$ e 480 $\mathrm{kg} \mathrm{ha}^{-1} \mathrm{ano}^{-1}$ ). Observou-se que a aplicação de $\mathrm{K}$, independentemente do ciclo, incrementou o peso do cacho, o número de mãos e de frutos por cacho, e o peso e o diâmetro do dedo do meio do cacho. O incremento da dose de $\mathrm{Mg}$ aumentou o peso do cacho no primeiro ciclo (SILVA et al., 2013). 
Os micronutrientes são requeridos pela bananeira em menores quantidades que os macronutrientes, mas seus efeitos na qualidade do fruto são extremadamente importantes. A ausência de B e Zn, nos planos de adubação, pode afetar o balanço nutricional da bananeira, visto que esses elementos regulam o potencial produtivo e a qualidade do fruto. Sánchez e Ortega (2006) fizeram uma pesquisa na zona bananeira de 'Magdalena', Colômbia, e encontraram respostas positivas à adubação com os micronutrientes $\mathrm{B}-\mathrm{Zn}$, tanto no primeiro ciclo (Williams), como em segundo ciclo (Gran Enano), evidenciadas por incrementos na produção e na melhoria dos componentes da qualidade, sendo as mais importantes a maior relação STT/ATT e a diminuição do número de frutos disformes.

Na região Amazônica do Brasil, foi estudado o efeito do B sobre o rendimento e a qualidade do fruto da banana 'Cavendish'. Avaliaram-se as doses: $\left(0 ; 4 ; 8\right.$ e $\left.12 \mathrm{~kg} \mathrm{ha}^{-1}\right)$, considerando-se dois ciclos de colheita. O B influenciou o rendimento de frutos, a relação polpa/casca e a resistência do fruto à penetração (MOREIRA et al., 2010).

Na Tabela 4, é apresentado um resumo dos principais efeitos dos elementos minerais sobre a qualidade dos frutos da bananeira.

\section{RESULTADOS DE PESQUISA COM A CULTURA DO MAMÃO}

$\mathrm{O} \mathrm{N}$ é um dos nutrientes que mais estão relacionados aos aumentos na produtividade do mamoeiro. No entanto, seu efeito sobre a qualidade dos frutos nem sempre tem-se mostrado evidente. Pelo anterior, foi conduzido um experimento para verificar o efeito do $\mathrm{N}$ sobre a qualidade de frutos do mamoeiro cv. Improved Sunrise Solo Line $72 / 12$. Foram estudadas três doses de N $(10 ; 20$ e $30 \mathrm{~g}_{\text {planta }}{ }^{-1}$ mês $\left.^{-1}\right)$, e duas fontes de N: sulfato de amônio (SA) e nitrato de amônio (NA). Obteve-se que o peso médio dos frutos, o $\mathrm{pH}$ e o teor de ácido cítrico não foram afetados pelas doses e fontes de N. Com o aumento das doses de N, o SA provocou decréscimo linear dos SSTs e a aplicação de NA promoveu maior produção de frutos com teor mais elevado de vitamina C (MARINHO et al., 2001).

Souza et al. (2009) avaliaram as características físicas e químicas de frutos de mamoeiro 'Tainung $\mathrm{n}^{\circ} 1$ ', sob aplicação de duas fontes nitrogenadas: sulfato de amônio (SA) e nitrato de cálcio (NC), durante o ciclo da cultura, na Bahia, Brasil. Foram testados os seguintes tratamentos: T1 - aplicação de SA em 100\% do ciclo do mamoeiro; T2 - aplicação de SA em 75\% do ciclo e de NC em $25 \%$ do mesmo;
T3 - aplicação de SA em 50\% do ciclo e de NC no restante; T4 - aplicação de SA em 25\% do ciclo e $75 \%$ de NC no restante; e T5 - 100\% do ciclo com NC. Os autores observaram que as diferentes fontes nitrogenadas e suas combinações afetaram a firmeza da polpa, a ATT e a relação SST/ATT. Quanto aos parâmetros físicos, o uso de SA em $100 \%$ do ciclo foi a melhor alternativa; entretanto, frutos de melhor qualidade química foram obtidos com aplicação de $\mathrm{NC}$ em até $50 \%$ do ciclo da cultura.

Brito Neto et al. (2011) analisaram a produtividade e a qualidade de frutos de mamoeiro 'Sunrise Solo' em função de doses de N, nas condições da localidade de Areia, Paraíba, Brasil. As doses de $\mathrm{N}$ empregadas foram $(0,0-111,2$ $-200-288,9-400$ g planta $\left.^{-1}\right)$. O N aumentou a produtividade, o peso médio dos frutos e o número de frutos por planta. $\mathrm{O}$ incremento nas doses de $\mathrm{N}$ melhorou o diâmetro, o comprimento do fruto e o teor de SST. O pH da polpa decresceu linearmente com o aumento das doses de N. Houve efeito positivo das doses de $\mathrm{N}$ sobre o teor de vitamina $\mathrm{C}$.

A aplicação de $\mathrm{P}$ e seu efeito sobre a qualidade das frutas do mamoeiro tem sido objeto de estudos. Assim, Nasution et al. (2011) avaliaram a resposta de seis cultivares de mamoeiro à adubação fosfatada na zona de Kalimantan, na Índia. As doses de $\mathrm{P}$ usadas foram: 100; 200 e $300 \mathrm{~g}$ de $\mathrm{P}_{2} \mathrm{O}_{5}$ planta $^{-1}$. Os resultados indicaram diferenças no crescimento e na produção entre cultivares. A aplicação de $\mathrm{P}$ afetou a altura das plantas, mas não teve efeito sobre outras variáveis de crescimento dessa frutífera e de qualidade do fruto.

$\mathrm{O}$ mamoeiro exige grande quantidade de $\mathrm{K}$ para alcançar boas produções e qualidade de frutos adequada. Por isso, Marinho et al. (2008) estudaram os efeitos de lâminas de irrigação e doses de K sobre a produtividade e a qualidade dos frutos do mamoeiro cv. Golden, na localidade de Linhares, Espírito Santo, Brasil. Os autores consideraram cinco lâminas de irrigação: 50; 70; 90; 110 e 130\% da ETo, e quatro doses de $\mathrm{K}$ : 30; 42; 54 e 66 g de $\mathrm{K}_{2} \mathrm{O}$ por planta ao mês. Durante os 11 meses e 21 dias de colheita, a produtividade média da cv. Golden foi de 79,4 $\mathrm{t} \mathrm{ha}^{-1}$, com média de 96 frutos por planta, que, no estádio I de maturação, apresentavam massa de $404 \mathrm{~g}$, teor médio de SST de $10,11^{\circ}$ Brix e firmeza da polpa e do fruto de $79,80 \mathrm{~N}$ e $126,19 \mathrm{~N}$, respectivamente.

Foi conduzido um experimento durante três anos na localidade de Tamil Nadu, na Índia, para estudar o efeito do K sobre o crescimento, a produção e a qualidade do fruto. As doses de K foram: 0; 150; 300 e 450 g K$_{2} \mathrm{O}$ planta $^{-1}$ ano-1), juntamente com 300 $\mathrm{g}$ de $\mathrm{N}$ e $300 \mathrm{~g}$ de $\mathrm{P}_{2} \mathrm{O}_{5}$ planta ${ }^{-1}$ ano $^{-1}$. Houve efeito 
do $\mathrm{K}$ sobre o crescimento e a produção da planta. A nutrição potássica melhorou as características de qualidade dos frutos, como SST, espessura da polpa e teor de carotenoides. Os autores indicam que a adubação com $\mathrm{N}=300, \mathrm{P}_{2} \mathrm{O}_{5}=300$ e $\mathrm{K}_{2} \mathrm{O}=300 \mathrm{~kg}$ ha $^{-1}$ $\mathrm{ano}^{-1}$ é recomendada para se obter maior rendimento com frutos de qualidade (KUMAR et al., 2010).

$\mathrm{O}$ efeito da adubação combinada dos principais macronutrientes nas características de qualidade dos frutos do mamoeiro tem sido abordado, e os resultados têm sido variados. Deste modo, Allam et al. (2000) avaliaram a adubação com NPK em mamoeiro 'Solo' na localidade de Pietermaritzburg, Africa do Sul, não detectando efeito do N, P e K sobre a qualidade do fruto. Marinho et al. (2012) analisaram os efeitos do espaçamento e do nível de adubação NPK sobre alguns atributos de qualidade dos frutos do híbrido do grupo 'Formosa' UENF/ CALIMAN-01(UC01), na localidade de Linhares, Espírito Santo, Brasil. Os autores consideraram três espaçamentos de plantio entre plantas $\left(E_{1}=1,80\right.$ $\mathrm{m} ; \mathrm{E}_{2}=2,25 \mathrm{~m}$, e $\left.\mathrm{E}_{3}=2,70 \mathrm{~m}\right)$, cinco níveis de adubação NPK: convencional $\left(\mathrm{A}_{1}=80 \%\right.$ do padrão da empresa $(\mathrm{PE}) ; \mathrm{A}_{2}=100 \% \mathrm{PE} ; \mathrm{A}_{3}=120 \% \mathrm{PE}$; $\mathrm{A}_{4}=140 \% \mathrm{PE}$, e $\mathrm{A}_{5}=160 \% \mathrm{PE}$ ), e três períodos de avaliação (junho, agosto e outubro de 2007). O padrão de adubação NPK da empresa (PE) consistiu em 350; 105 e $660 \mathrm{~kg} \mathrm{ha}^{-1} \mathrm{ano}^{-1}$ de sulfato de amônio $(20 \%$ de $\mathrm{N})$, superfosfato simples $\left(18 \%\right.$ de $\left.\mathrm{P}_{2} \mathrm{O}_{5}\right)$ e cloreto de potássio $\left(60 \%\right.$ de $\left.\mathrm{K}_{2} \mathrm{O}\right)$, respectivamente. O melhor desempenho foi obtido pelas combinações $\mathrm{E}_{1} \mathrm{~A}_{1}$ ou $\mathrm{E}_{2} \mathrm{~A}_{1}$. Os tratamentos resultaram em frutos com atributos de qualidade superiores, além de proporcionar redução nos gastos com adubação NPK e menor impacto ambiental em função da aplicação excessiva de adubos ao solo.

$\mathrm{O} \mathrm{Ca}$ tem sido relatado como fundamental para a formação e a preservação da qualidade do fruto do mamoeiro. Assim, Qiu et al. (1995) estudaram a extração de Ca pelos frutos do mamoeiro 'Sunset' durante seu amadurecimento. Evidenciaram que a aplicação de $\mathrm{Ca}$ no solo nem sempre incrementou o conteúdo deste nutriente na polpa do fruto. $\mathrm{O}$ aumento na aplicação de $\mathrm{K}$ e $\mathrm{N}$ reduziu o teor de $\mathrm{Ca}$ na polpa. $\mathrm{O}$ uso de $\mathrm{CaCl}_{2}$ para incrementar o $\mathrm{Ca}$ no mesocarpo via aspersão (na pré-colheita) ou a infiltração (na pós-colheita) não tiveram sucesso. $\mathrm{O}$ conteúdo de Ca esteve correlacionado positivamente à firmeza e negativamente ao amolecimento dos frutos. Baixa associação foi determinada entre a firmeza e as relação $\mathrm{Ca} / \mathrm{K}, \mathrm{Ca} / \mathrm{Mg}$ e $\mathrm{Ca} / \mathrm{K}+\mathrm{Mg}$.

Foi avaliado o efeito de aplicações précolheita e pós-colheita de cálcio em mamão "Criolla" sobre a severidade da antracnose (Coletotrichum gloeosporioides) e variáveis de qualidade do fruto. Os tratamentos pré-colheita foram: aspersão na planta de $\mathrm{CaCl}_{2}$ a $1 \%$ e $4 \%$, aplicação de $\mathrm{CaCl}_{2}\left(1 \mathrm{t} \mathrm{ha}^{-1}\right)$ e controle $(0 \%$ de $\mathrm{Ca})$. Os tratamentos pós-colheita foram: imersões por 5 minutos com $0 \%, 1 \%$ e $4 \%$ de $\mathrm{CaCI}_{2}$. A aplicação na pré-colheita não teve efeito sobre a severidade da doença. A maior firmeza da polpa e da casca correspondeu ao tratamento com $1 \%$ .Quando foram usados 4\%, acelerou-se a maturação. $\mathrm{O}$ uso de $\mathrm{Ca}$ na pós-colheita diminuiu a severidade de $23 \%$ para $12 \%$ e, para $11 \%$ com $0 \%, 1 \%$ e $4 \%$ de $\mathrm{Ca}$, respectivamente. A concentração de $4 \%$ pode ter atrasado a maturação, resultando em menor SST (SABORIO et al., 2000).

Campostrini et al. (2005) realizaram um estudo com $\mathrm{Ca}$, em plantio comercial localizado em São Francisco do Itabapoana, Rio de Janeiro, Brasil. Foram feitas relações entre algumas variáveis do clima (temperatura, déficit de pressão de vapor, precipitação pluvial e radiação solar global) e os teores de Ca na planta [limbo, pecíolo, pedúnculo, epicarpo não exposto (face do fruto próxima ao tronco) e epicarpo exposto (face do fruto oposta ao tronco)] com a incidência da mancha Fisiológica de Mamão (MFM). Estes autores determinaram que a amplitude térmica foi a variável do clima que mais se relacionou com a incidência da MFM e propõem que teores baixos de $\mathrm{Ca}$ no fruto poderiam causar desestabilização na parede celular, o que facilitaria o extravasamento do látex e provocaria a MFM.

Mahmud et al. (2008) trataram frutos de mamão com soluções de Cloreto de Cálcio a 1,5\%; 2,5\% e 3,5\% por meio de imersão e infiltração a vácuo $(-33 \mathrm{kPa})$ e o controle $(0 \%)$, para analisar os efeitos do $\mathrm{Ca}$ sobre as características de qualidade pós-colheita. Após 21 dias de armazenamento a $13 \pm 1$ ${ }^{\circ} \mathrm{C}$, os frutos foram retirados do armazenamento para análise físico-química, o qual também foi realizado após cinco dias sob condições ambiente. A infiltração com as diferentes concentrações de cálcio prolongou a vida útil de armazenamento, já que diminuiu os processos de maturação e manteve a qualidade do mamão. A infiltração foi mais efetiva que a imersão. A incidência de doenças foi menor quando foram infiltrados com $2,5 \%$ de $\mathrm{Ca}$. Os autores sugerem que a infiltração do mamão com 2,5\% de Ca é recomendável devido que nessa concentração o Ca desempenhou seus efeitos sobre a inibição do processo de amadurecimento, senescência e perda da firmeza dos frutos.

Os micronutrientes desenvolvem um papel determinante nas características de qualidade dos frutos do mamoeiro. Deste modo, ao examinar o efeito de diferentes níveis de $\mathrm{B}$ (bórax em 0,25 e 0,50\%), 
$\mathrm{Zn}\left(\mathrm{ZnSO}_{4}\right.$ 0,25 e 0,50\%) e suas combinações sobre o crescimento, a produção e a qualidade do mamão cv. Ranchi na localidade de Cooch Behar, na West Bengal (Bengala Ocidental), observou-se que a aplicação de bórax a $0,50 \%+\mathrm{ZnSO}_{4}$ em $0,25 \%$ foi considerado o melhor tratamento, resultando em crescimento máximo das plantas (altura $=171,62 \mathrm{~cm}$ e diâmetro do caule $=39,74 \mathrm{~cm}$ ), com rendimento máximo de frutos $\left(37,20 \mathrm{~kg}_{\text {planta }}{ }^{-1}\right)$. Do mesmo modo, obtiveram-se os melhores valores para os SSTs $\left(6,81^{\circ}\right.$ Brix), açúcares totais $(6,88 \%)$, ácido ascórbico $(57,11 \mathrm{mg} / 100 \mathrm{~g}), \beta$ caroteno (ug/100 g), bem como a relação SST/ATT $(58,41)($ SINGH et al., 2010)

Ao analisar a qualidade de frutos do mamoeiro 'Sunrise Solo' em função de doses de B, nas condições da localidade de Areia, Paraiba, Brasil, usando B nas doses: $\left(0,0 ; 0,83 ; 1,5 ; 2,16\right.$ e 3,0 g planta $\left.^{-1}\right)$, observouse que este micro-nutriente melhorou o diâmetro e o comprimento dos frutos, assim como o teor de SST (BRITO NETO et al., 2011).

$\mathrm{Na}$ Tabela 5, estão resumidos como os elementos minerais afetam a qualidade do fruto do mamoeiro.

TABELA 1- Resumo de algumas funções dos elementos minerais que agem na formação e na conservação da qualidade dos frutos.

\begin{tabular}{|c|c|c|}
\hline Elemento & Compostos/Funções & Fonte \\
\hline Nitrogênio & $\begin{array}{l}\text { Faz parte de aminoácidos, proteínas, coenzimas, ácidos } \\
\text { nucleicos e vitaminas. Participa da fotossíntese, } \\
\text { respiração,multiplicação e diferenciação celular. }\end{array}$ & Malavolta (2006) \\
\hline Fósforo & $\begin{array}{l}\text { Atua no metabolismo energético (ATP). } \\
\text { Age nas reações de sínteses de açúcares fosfatados, } \\
\text { ácidos nucleicos e coenzimas. } \\
\text { Atua na formação e movimentação de carboidratos. }\end{array}$ & $\begin{array}{l}\text { Epstein e Bloom } \\
\quad(2006)\end{array}$ \\
\hline Potássio & $\begin{array}{l}\text { Ativador de enzimas da fotossíntese e respiração. } \\
\text { Determina a turgescência das células. Balanço de sais e água. } \\
\text { É muito importante para o metabolismo dos carboidratos } \\
\text { (piruvato-kinasa e fosfato-kinasa). } \\
\text { A atividade da amido-sintetaza depende do K. } \\
\text { Incrementa a fixação do } \mathrm{CO}_{2} \text { e promove o transporte de } \\
\text { fotoassimilados }\end{array}$ & $\begin{array}{l}\text { Malavolta (2006) } \\
\text { Epstein e Bloom } \\
\quad(2006)\end{array}$ \\
\hline Cálcio & $\begin{array}{l}\text { Formação da parede celular, regulação da funcionalidade } \\
\text { da membrana celular, constituição da lamela média, além } \\
\text { de ativar vários sistemas enzimáticos. }\end{array}$ & $\begin{array}{l}\text { Mengel e Kirkby } \\
\quad(2000)\end{array}$ \\
\hline Magnésio & $\begin{array}{l}\text { Participa da clorofila (fotossíntese). Ativação de enzimas } \\
\text { envolvidas na respiração, fotossíntese e síntese de ADN } \\
\text { e ARN. }\end{array}$ & Malavolta (2006) \\
\hline Enxofre & $\begin{array}{l}\text { Participa de aminoácidos e de todas as proteínas; atua na } \\
\text { fotossíntese, respiração e fixação de } \mathrm{N} \text {. }\end{array}$ & $\begin{array}{l}\text { Epstein e Bloom } \\
\quad(2006)\end{array}$ \\
\hline Micronutrientes & $\begin{array}{l}\text { Atuam na catálise e na ativação de enzimas; transporte } \\
\text { de carboidratos; germinação dos grãos de pólen na fruti- } \\
\text { ficação (B) }\end{array}$ & $\begin{array}{l}\text { Malavolta (2006) } \\
\text { Epstein e Bloom } \\
\quad(2006)\end{array}$ \\
\hline
\end{tabular}




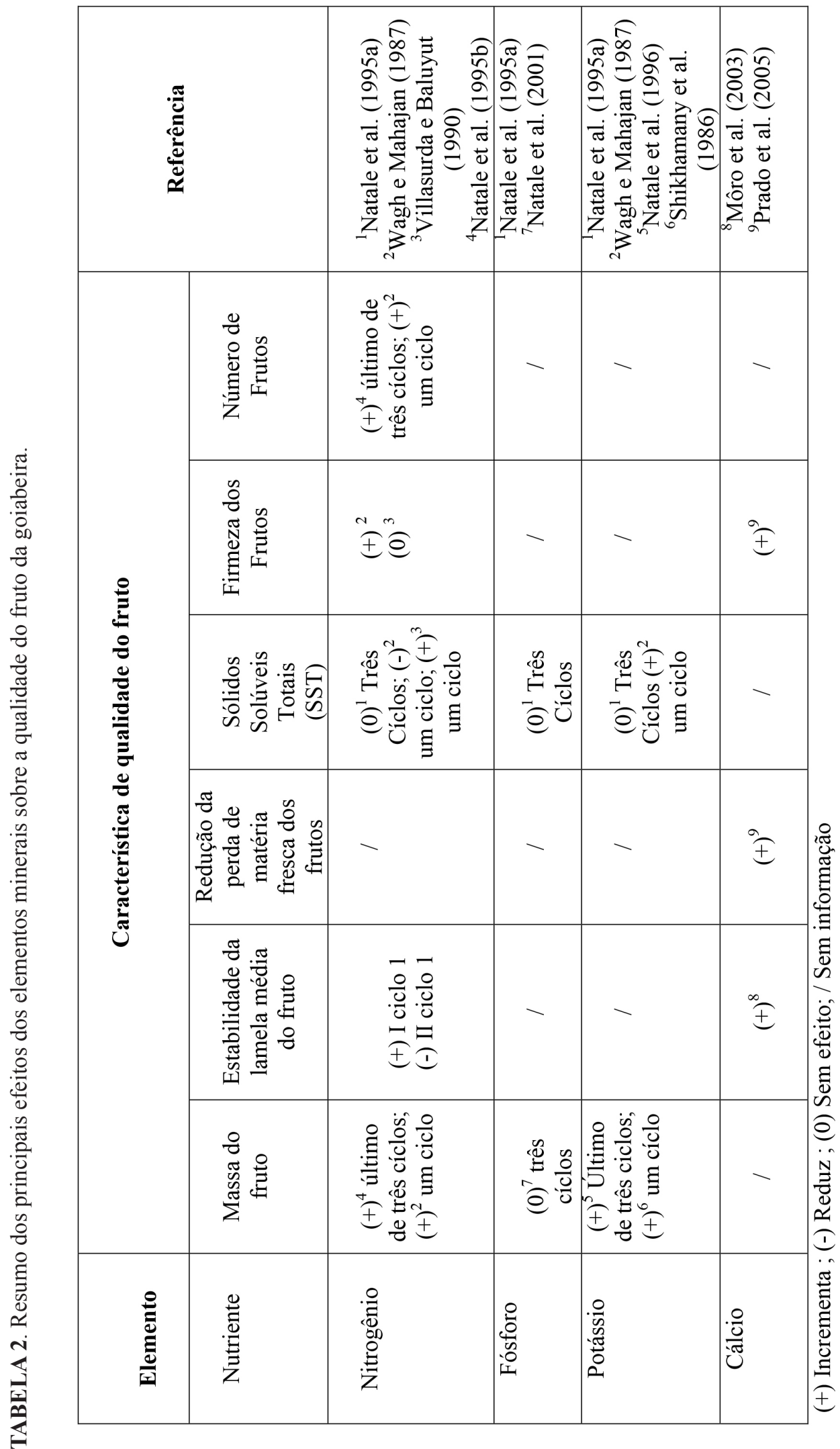




\begin{tabular}{|c|c|c|c|c|c|c|}
\hline \multicolumn{2}{|c|}{ 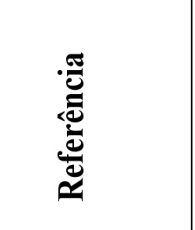 } & 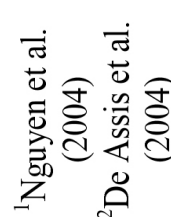 & 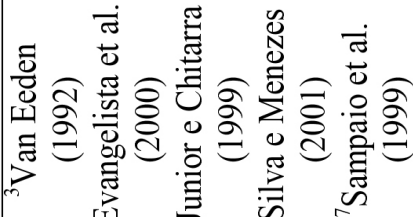 & 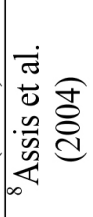 & 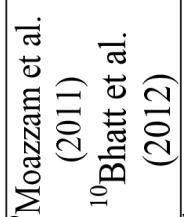 & 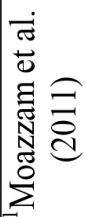 \\
\hline \multirow{10}{*}{ 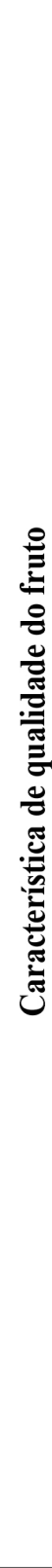 } & 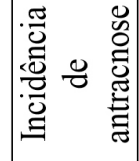 & I & - & - & - & - \\
\hline & 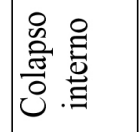 & II & 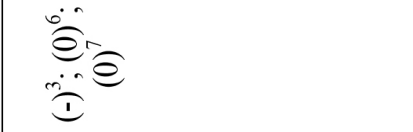 & $\stackrel{\infty}{I}$ & - & - \\
\hline & 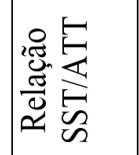 & - & - & - & - & - \\
\hline & 㫐 & $\vec{e}$ & - & - & $\overbrace{}^{ \pm} \stackrel{\circ}{ \pm}$ & $\stackrel{F}{I}$ \\
\hline & $\bar{n}$ & $\overrightarrow{\mathrm{e}}$ & - & - & II & II \\
\hline & 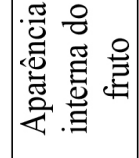 & & "ê & - & - & - \\
\hline & 官 & II & - & - & - & - \\
\hline & 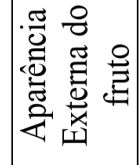 & - & $\stackrel{n}{ \pm}$ & - & - & - \\
\hline & 苞 & - & 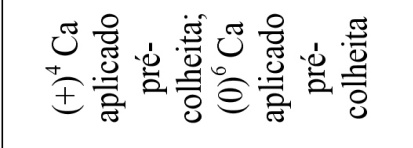 & - & - & - \\
\hline & 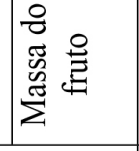 & - & - & - & I & - \\
\hline & 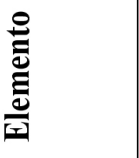 & 象 & $\frac{.0}{\frac{0}{0}}$ & 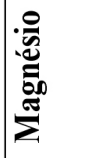 & ம & సี \\
\hline
\end{tabular}




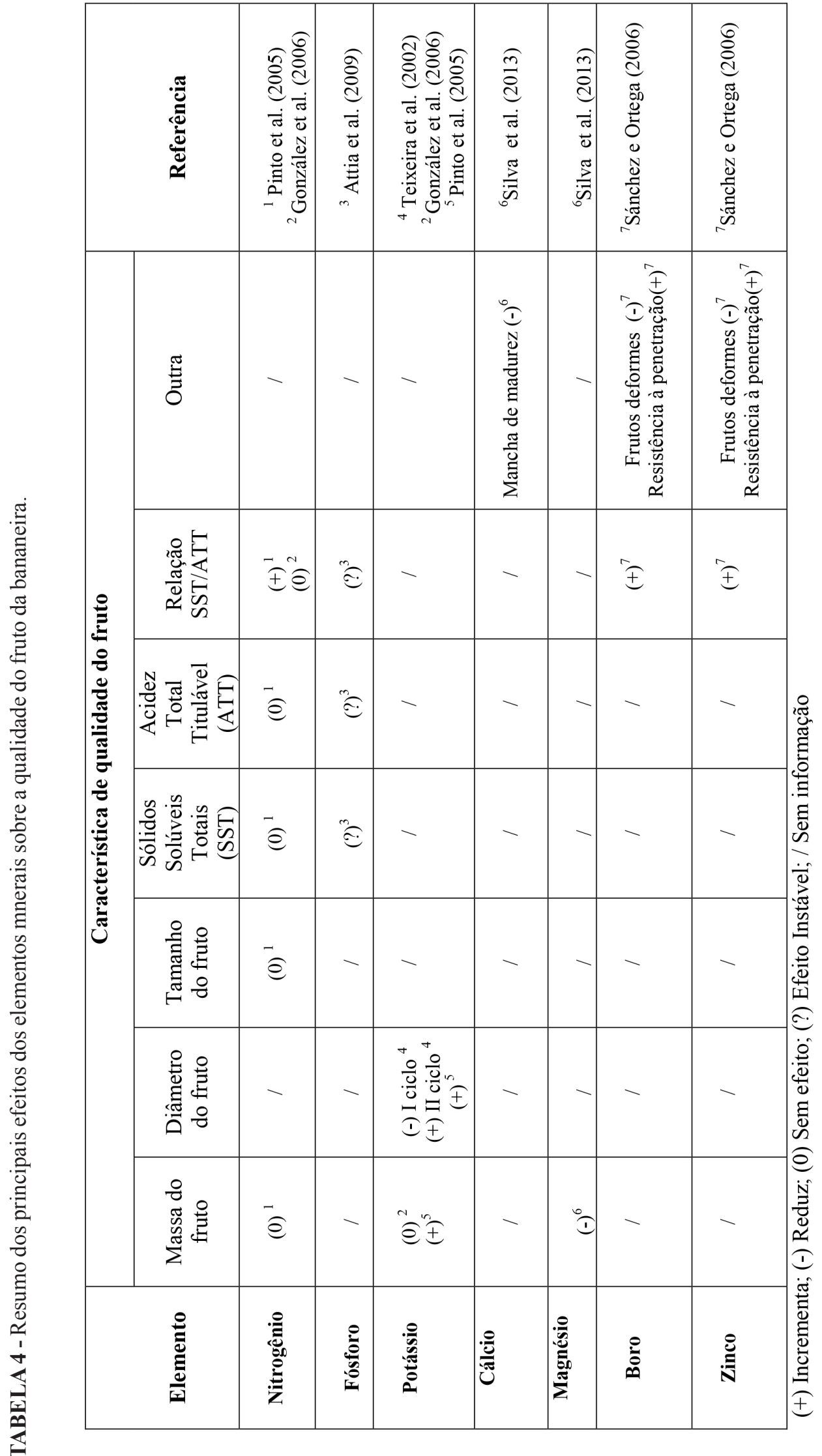




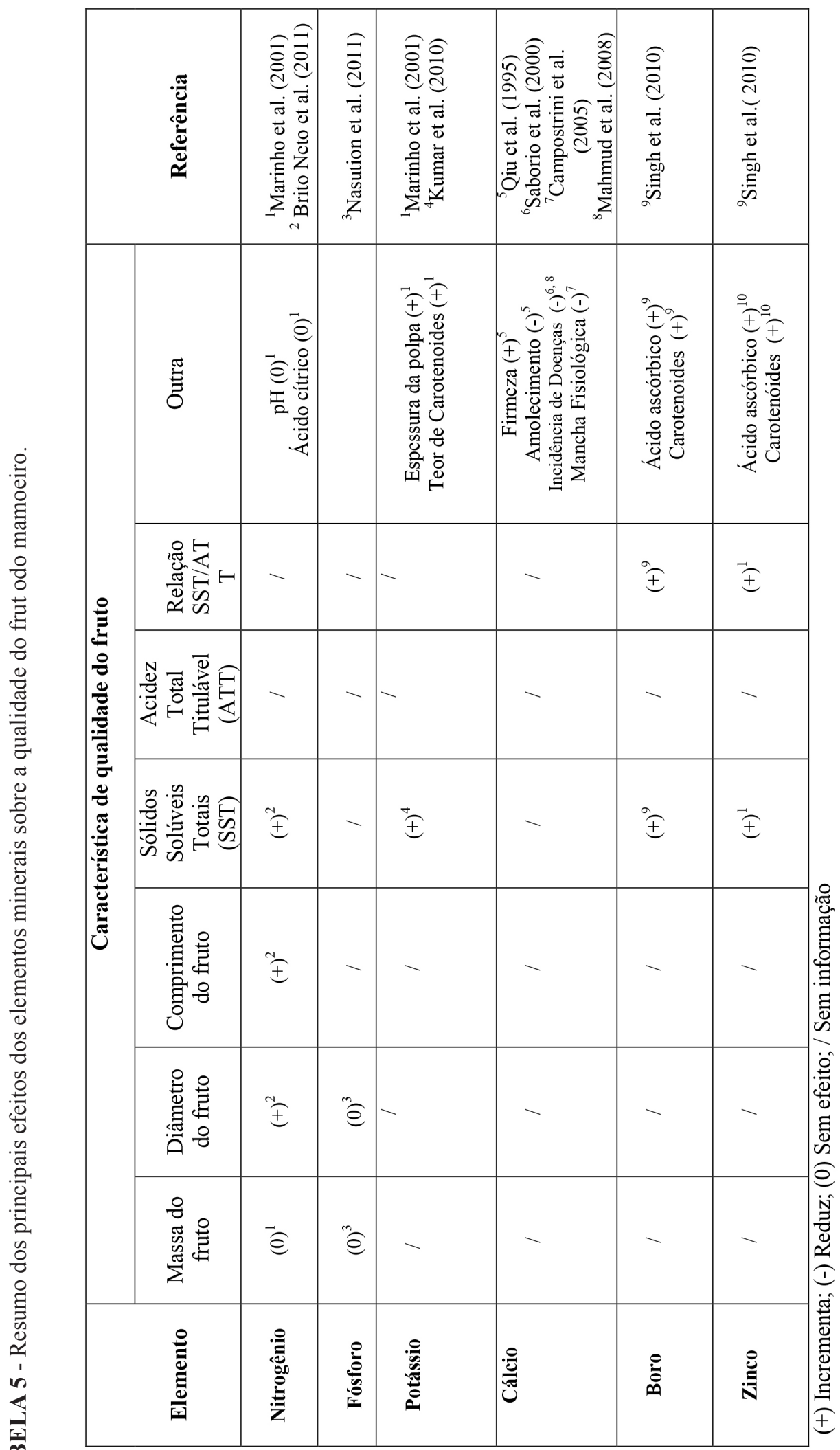




\section{REFERÊNCIAS}

AL-HARTHI, K.; AL-YAHYAI, R. Effect of NPK fertilizer on growth and yield of banana in northern Oman. Journal of Horticulture and Forestry, Peshawar, v.1, n.8, p. 160-167, 2009.

ALLAN, P.; TAYLOR, N.; DICKS, H. Fertilization of 'Solo' papayas with nitrogen, phosphorus and potassium. Acta Horticulturae, The Hague, n.511, p.27-33, 2000.

ASSIS, J. S.; SILVA, D. J.; MORAES, P. L. D. Equilíbrio nutricional e distúrbios fisiológicos em manga 'Tommy Atkins'. Revista Brasileira de Fruticultura, Jaboticabal, v. 26, n. 2, p. 326-329, 2004.

ATTIA, M.; AHMED, M.A.; EL-SONBATY, M.R. Use of biotechnologies to increase growth, productivity and fruit quality of 'Maghrabi' banana under different rates of phosphorus. World Journal of Agricultural Sciences, Deira, v.5, n.22,p. 211220, 2009.

BHATT, A.; MISHRA, N.; MISHRA, D.; SINGH, C. Foliar application of potassium, calcium, zinc and boron enhanced yield, quality and shelf life of mango. HortFlora Research Spectrum, New Delhi, v.1, n.4, p.300-305, 2012.

BRITO NETO J. de; PEREIRA, W.; CAVALCANTI, L.; ARAÚJO, R.; de LACERDA, J. Produtividade e qualidade de frutos de mamoeiro 'Sunrise Solo' em função de doses de nitrogênio e boro. Semina. Ciências Agrárias, Londrina, v.32, n.1, p.69-80, 2011.

CAMPOSTRINI, E.; LIMA, H.; DE OLIVEIRA, J.; MONNERAT, P.; MARINHO, C. Teores de Ca e variáveis meteorológicas: relações com a incidência da mancha fisiológica do mamão no norte Fluminense. Bragantia, Campinas, v.64. n.4, p.601-613, 2005.

CRISOSTOMO, L.; MONTENEGRO, A.; de SOUSA NETO, J.; DE LIMA, R. Influência da adubação NPK sobre a produção e qualidade dos frutos de bananeira cv. Pacovan. Revista de Ciência Agronômica, Fortaleza, v.39, n.1, p. 45-52, 2008.
DÍAZ, A.; CAYÓN, G.; MIRA, J. Metabolismo del calcio y su relación con la "Mancha de madurez" del fruto de banano. Una revisión. Agronomía Colombiana, Bogotá, v.25, n.2, p.280-287, 2007.

DIETZ, T.H.; THIMMA RAJU, K.R.; JOSHI, S.S. Structure and development of cuticle and lenticels in fruits of certain cultivars of mango. Acta Horticulturae, The Hague, v.231, p.457-460, 1988.

EPSTEIN, E.; BLOOM, A. J. Nutrição mineral de plantas: princípios e perspectivas. Londrina: Ed. Planta, 2006. 401p.

EVANGELISTA, R.M. Qualidade de mangas 'Tommy Atkins' armazenadas sob refrigeração e tratadas com cloreto de cálcio pré-colheita. 1992. 129f. Tese (Doutorado em Ciências dos Alimentos) - Universidade Federal de Lavras, Lavras, 1992.

EVANGELISTA, R.M.; CHITARRA, A.B.; CHITARRA, M.I.F. Mudanças na ultraestrutura da parede celular de mangas 'Tommy Atkins' tratadas com cloreto de cálcio na pré-colheita. Revista Brasileira de Fruticultura, Jaboticabal, v.24, n.1, p.254-257, 2002.

EVANGELISTA, R.M.; CHITARRA, A.D.; CHITARRA, M.I.F. Influência da Aplicação PréColheita de Cálcio na Textura e na Atividade das Enzimas Poligalacturonase, pectinametilesterase e b- Galactosidase de Mangas 'Tommy Atkins' Armazenadas sob Refrigeração. Ciência e Agrotecnologia, Lavras, v.24, p.174-181, 2000.

FAO. Organização das Nações Unidas para Agricultura e Alimentação. Disponível em: <http:// www.fao.org.br/>. Acesso em: 26 nov. 2009.

GANESHAMURTHY, N.; SATISHA, G.; PRAKASH PATIL, P. Potassium Nutrition on yield and quality of fruit crops with special emphasis on banana and grapes. Karnataka Journal of Agricultural Science, Cambridge, v.24, n.1, p.29-38, 2011.

GONZÁLEZ, H.; LUNA, R.G.; QUINTERO, F. V. Respuesta del plátano África 1 a la fertilización edáfica con nitrógeno y potasio. Agronomia, Caldas, v.14, n.11, p.81-88, 2006.

IBRAF - Instituto Brasileiro de Frutas. Panorama da cadeia produtiva de frutas em 2012 e projeções para 2013. São Paulo. 127 p. 
JÚNIOR, M.F.; CHITARRA, A.B. Efeito da aplicação do cloreto de cálcio nos frutos da manga 'Tommy Atkins' tratados hidrotermicamente. Pesquisa Agropecuária Brasileira, Brasília, v.34, n.5, p.761-769, 1999.

KUMAR, N.; SOORIANATHASUNDARAM, K.; MEENAKSHI, N.; MANIVANNAN, M.; SURESH, J.; NOSOV, D. Balanced fertilization in papaya (Carica papaya 1.) for higher yield and quality. Acta Horticulturae, The Hague, v.851, p.357-362, 2010.

LÉCHAUDEL, M.; JOAS, J. An overview of preharvest factors influencing mango fruit growth, quality and postharvest behavior. Brazilian Journal of Plant Physiology, Piracicaba, v.19, n.4, p.287298, 2007.

MAHMUD, T.; ERYANI-RAQEEB, A.; OMAR,S S.; ZAKI, M.; ABDUL-RAHMAN, A. Effects of different concentrations and applications of calcium on storage life and physicochemical characteristics of papaya (Carica papaya L.). American Journal of Agricultural and Biological Sciences, Netherlands, v.3, n.3, p. 526-533, 2008.

MAIA, V.; SALOMÃO, L.; CANTARUTTI, R.; VENEGAS, V.; COUTO, F. Efeitos de doses de nitrogênio, fósforo e potássio sobre os componentes da produção e a qualidade de bananas 'Prata-Anã' no distrito agroindustrial de Jaíba. Revista Brasileira de Fruticultura, Jaboticabal, v.25, n.2, p.319-322, 2003.

MALAVOLTA, E. Manual de nutrição mineral de plantas. Piracicaba: Ceres, 2006. 638p.

MARINHO, A.; BERNARDO, S.; DE SOUSA, E.; PEREIRA, M.; MONNERAT, P. Produtividade e qualidade de frutos de mamão cultivar 'Golden' sob diferentes lâminas de irrigação e doses de potássio no norte do Espírito Santo. Engenharia Agrícola, Jaboticabal, v.28, n.30, p.417-426, 2008.

MARINHO, C.; de OLIVEIRA, M.; MONNERAT, P.; VIANNI, R.; MALDONADO, J. Fontes e doses de nitrogênio e a qualidade dos frutos do mamoeiro. Scientia Agricola, Piracicaba, v.58, n.2, p.345-348, 2001.
MARSCHNER, H. Mineral nutrition higher plants. London: Academic Press, 1995. 674p.

MARTINS, A.; TEIXEIRA, L.; SUGUINO, E., HASHIMOTO, J., NARITA, N. Irrigação e adubação potássica via fertirrigação em bananeira 'Willians' - produção e qualidade de frutos. Revista Brasileira de Fruticultura, Jaboticabal, p.743751, 2011. Volume Especial.

MENGEL, K.; KIRKBY, E.A. Principios de nutrición vegetal. Basel: International Potash Institute, 2000. 692p.

MOAZZAM, A.; TAHIR, F. M.; SHAHZAD, J.; MAHMOOD, N. Effect of foliar application of micronutrients on the quality of mango (Mangifera indica L.) cv. Dusehri fruit.). Mycopathologia, Dordrecht, v.9, n.1, p. 25-28, 2011.

MORAES, P.L.D.; ASSIS, J.S.; SILVA, D.J. Equilíbrio Nutricional e Distúrbios Fisiológicos em Manga Tommy Atkins. In: CONGRESSO BRASILEIRO DE FRUTICULTURA, 17., 2002, Belém. Resumos... Jaboticabal: SBF, 2002.CDROM.

MOREIRA, A.; DE CASTRO, C.; FAGERIA, N. Efficiency of boron application in an Oxisol cultivated with banana in the central Amazon. Anais da Academia Brasileira de Ciências, Rio de Janeiro, v.82, n.4, p.1137-1145, 2010.

MÔRO, F.V.; NATALE, W.; DAMIÃO FILHO, C.F.; PRADO, R.M. Morfologia de frutos de goiabeira. Revista Brasileira de Fruticultura, Jaboticabal, v.25, p.32-34, 2003.

NASUTION, F.; NOFLINDAWATI, M.; BUDIYANTI, T. The response of five tidal swamp grown papaya cultivars from the collection of the Indonesian tropical fruit research institute (ITFRI) to phosphorus fertilization. Journal of Fruit and Ornamental Plant Research, Skierniewice, v.19, n.1, p.137-144, 2011.

NATALE, W.; COUTINHO, E. L. M.; BOARETTO, A. E.; CENTURION, J. F. Resposta da goiabeira (Psidium guajava L.) cv. Paluma em formação à adubação fosfatada. Revista Brasiliera de Fruticultura, Jaboticabal, v.23, n.1, p.92-96, 2001. 
NATALE, W.; COUTINHO, E. L. M.; BOARETTO, A. E.; PEREIRA, F. M.; OIOLI, A. A. P.; SALES, L. Nutrição e adubação potássica na cultura da goiabeira. Revista Brasileira de Ciência do Solo, Viçosa, MG, v.20, p.247-250, 1996.

NATALE, W.; COUTINHO, E. L. M.; PEREIRA, F. M.; BOARETTO, A. E.; OIOLI, A. A. P.; SALES, L. Adubação nitrogenada na cultura da goiabeira. Revista Brasileira de Fruticultura, Jaboticabal, v.17, n.2, p.7-15, 1995 b.

NATALE, W.; COUTINHO, E. L. M.; PEREIRA, F. M.; JÚNIOR, M. M.; MARTINS, M.C. Efeito da adubação N, P e K no teor de sólidos solúveis totais de frutos de goiabeira (Psídium guajava, L.).

Revista Alimentos e Nutrição, Araraquara, v.6, p.69-75, 1995a.

NATALE, W.; ROZANE, D. E.; PARENT, L. E.; PARENT, S.-E. Acidez do solo com calagem em pomares de frutíferas tropicais. Revista Brasileira de Fruticutura, Jaboticabal, v. 34, n. 4, p. 1294$1306,2012$.

NGUYEN, H.; HOFMAN, P.; HOLMES, R.; BALLY, I.; STUBBINGS, B.; MCCONCHIE, $\mathrm{R}$. Effect of nitrogen on the skin colour and other quality attributes of ripe 'Kensington Pride' mango (Mangifera indica L.) fruit. Journal of Horticultural Science \& Biotechnology, Ashford, v.79, n.2, p.204-210, 2004.

PINTO; J.; de FARIA, C.; SILVA, D.; FEITOSA, J. Doses de nitrogênio e potássio aplicadas via fertirrigação em bananeira. Irriga, Botucatu, v.10, p.46-52, 2005.

PRADO, R. M.; NATALE, W.; SILVA, J. A. A. Liming and quality of guava fruit cultivated in Brazil. Scientia Horticulturae, Amsterdam, v.106, p.91-102, 2005.

QIU, Y.; NISHINA, M.; PAULL, R. Papaya fruit growth, calcium uptake, and fruit ripening. Journal of the American Society for Horticultural Science, Alexandria, v.120, n.2, p. 246-253. 1995.

RAIJ, B. van. Fertilidade do solo e adubação. São Paulo: Ceres, Potafós, 1991. 343p.
SABORIO, D.; SAENZ, V.; ARAUZ, L.; BERTSCH,

F. Efecto del calcio en aplicaciones precosecha y poscosecha sobre la severidad de antracnosis (Colletotrichum gloeosporioides) y la calidad de frutos de papaya (Carica papaya). Agronomía Costarricense, San José, v.24, n.2, p.77-88, 2000.

SAMPAIO, V.R.; SCARPARE FILHO, J.A.; KLUGE, R.A. Distúrbios fisiológicos da manga: efeito da aplicação de $\mathrm{Ca}$ em pulverização foliar. Scientia Agricola, Piracicaba, v.56, n.2, p.459-463, 1999.

SÁNCHEZ, M.; ORTEGA, O. Optimizing banana production and quality through micronutrients (B-Zn) based balanced nutrition. Joinville: ACORBAT, 2006

SHIKHAMANI, S.; IYER, C.; RAO, M.; SUBRAMANIAN, T. Variation in the seasonal nutrient status in relation to different yield patterns in guava cv. Allahabad Safeda. Indian Journal of Horticulture, Lucknow, v. 43, n.1/2, p.73-78, 1986.

SILVA, A.V.C.; MENEZES, J.B. Caracterização físico-química da manga 'Tommy Atkins' submetida à aplicação de cloreto de cálcio em pré-colheita e armazenamento refrigerado. Scientia Agricola, Piracicaba, v.58, n.1, p.67-72, 2001.

SILVA, I.; SILVA. J.; DE PINHO, P.; RODAS, C.; CARVALHO, J. Vegetative development and yield of the banana cv. 'Prata-Anã' as a function of magnesium and potassium fertilization. IDESIA, Arica, v.31, n.2,p. 83-88, 2013.

SINGH, D.; GHOSH, S.; PAUL, P.; SURESH, S. Effect of different micronutrients on growth, yield and quality of papaya (Carica papaya L.) cv. Ranchi. Acta Horticulturae, The Hague, v.851, p.351-356, 2010.

SOUZA, T.; COELHO, E.; PAZ, V.; LEDO, C. Avaliação física e química de frutos de mamoeiro 'Tainung $\mathrm{n}^{\circ} 1$ ', fertirrigado com diferentes combinações de fontes nitrogenadas. Revista Brasileira de Ciência Agrária, Recife, v.4, n.2, p.179-184, 2009.

TEIXEIRA, L.; NATALE, W.; RUGGIERO, C. Nitrogen and potassium fertilization of 'Nanicão' banana (Musa AAA Cavendish subgroup) under irrigated and non-irrigated conditions. Acta Horticulturae, The Hague, v.575, p.771-779, 2002. 
VAN EEDEN, S.J. Calcium infiltration as a possible postharvest treatment to increase storage potential of mango fruit. South African Mango Growers' Association Yearbook, Tzaneen, v. 12, p. 26-27, 1992.

VILLASURDA, P. J.; BALUYUT, N. M. Growth and yield of guava (Psidium guajava L.) as affected by different levels and sources of organic and inorganic fertilizers. USM College Agriculture of Research Journal, Kabacan, v.1, p.18-33, 1990.

WAGH, A. N.; MAHAJAN, P. R. Effect of nitrogen, phosphorus and potassium on quality of guava $\mathrm{cv}$. Sardar. Current Research Report, Singapore, v.3, p. 103-106, 1987.

WALLING, M.; SANYAL, D. Effect of various levels of nitrogen and potassium on flowering, fruit retention, yield and physico-chemical characteristics of guava (Psidium guajava L.) cv. Allahabad Safeda. Crop Research, Hisar, v.9, n.2, p.272-276, 1995.
WEBER, O.; MONTENEGRO, A.; NUNES, I.; SILVA, E.; SOARES, I.; CRISÓSTOMO, L. Adubação nitrogenada e potássica em bananeira 'Pacovan' (Musa AAB, Subgrupo prata) na chapada do Apodi, Estado do Ceará. Revista Brasileira de Fruticultura, Jaboticabal, v.28. n.1, p.154-157, 2006.

WEERASINGHE, P.; PREMALAL, N. Influence of potassium fertilization of growth and yield of Embul Banana (Musa spp. AAB Group) grown in Rhodudalfs under irrigated conditions. Annals of the Sri Lanka Department of Agriculture, Gannoruwa, v.4, p.109-117, 2002. 